\title{
Influence of Optimisation Target Functions on Synchronous Reluctance Machines Design
}

\author{
Oğuz Korman \\ PEMC Research Group \\ University of Nottingham \\ Nottingham,UK \\ oguz.korman@nottingham.ac.uk
}

\author{
Mauro di Nardo \\ PEMC Research Group \\ University of Nottingham \\ Nottingham,UK \\ mauro.dinardo4@nottingham.ac.uk
}

\author{
Michele Degano \\ PEMC Research Group \\ University of Nottingham \\ Nottingham,UK \\ michele.degano@nottingham.ac.uk
}

\author{
Chris Gerada \\ PEMC Research Group \\ University of Nottingham \\ Nottingham,UK \\ chris.gerada@nottingham.ac.uk
}

\begin{abstract}
Synchronous reluctance machines (SynRel) are becoming very attractive for different applications because of their reluctance nature, easy manufacturability and low cost. Their design still represents a challange because of the many degrees of freedom that their rotor structure presents. Furthermore, in order to obtain a design with defined electromagnetic characteristics and low torque ripple machine geometry is needed to be optimised. In this paper, three different optimisations are performed on 6 poles SynRel motor with three flux barriers per pole. The aim of the work is to show the effect of the objective selection on the optimization process. An automatic procedure has been applied coupling finite element analysis with an optimization algorithm that is working towards the competitive targets of maximazing the torque, while minimizing the torque ripple and losses. The effects of these objectives on the geometrical variables are investigated in detail. The outcome of the analysis show how the problem definition heavily affects the obtained results. This gives useful insights on how to approach SynRel rotor design.
\end{abstract}

Keywords-Synchronous reluctance, optimization

\section{INTRODUCTION}

Synchronous reluctance (SynRel) machines have gained increasing interest in industrial applications thanks to their low cost and good electromagnetic characteristics [1]. In the past decade, with the development of power electronics and control techniques, SynRel motors became a competitive alternative to induction machines, which are widely used in industry and investigated by many authors [2]-[6]. Their torque production is based on the reluctance concept, this tends to align the anisotropic rotor with the magnetic field produced by the stator windings. Thanks to this, SynRel machines do not have any rotor Joule or permanent magnet losses, which are present in other machines such as induction, salient pole and permanent magnet machines. This leads to the intrinsic benefit of high efficiency and reduced rotor temperature.

There are many rotor geometries proposed in the literature for synchronous reluctance rotors [7]-[10] where the main idea is to create a difference in reluctance between d-axis and q-axis, by creating a rotor anisotropy that maximises the reluctance in the q-axis while reducing the $\mathrm{d}$-axis one. Undoubtedly, this is not a straight forward task as the rotor shape can be represented with a large number of geometrical parameters. These can lead to a modification of the machine's electromechanic performance and other important design factors (i.e. torque ripple and power factor), which makes the design process a challenging optimisation problem [11]. It also has to be noted that due to the anisotropic nature of the SynRel motors, most of the output characteristics are concurrent to each other [12][13]. For example, an increased torque output might result in a greater saliency ratio, but an increased saturation in the machine, thus higher iron losses and lower efficiency. Therefore, when the machine needs to be designed for manufacturing, a multi-objective multivariable optimisation process is mandatory, in order to obtain a solution that meets the application requirements.

Many studies show optimisation of SynRel machines considering single or multi-physics aspects and operating points with a variable number of rotor parameters [14], [15]. In [13] and [16], a detailed investigation of the most important characteristics of a SynRel rotor is shown. It has been demonstrated how the ratio of air/iron on the q-axis (insulation ratio) and the placement of the barriers have seperate effects on average torque and torque ripple, respectively. The number of variables representing the geometry depend on the desired degree of freedom in the design process.

This paper aims to identify the influence of both rotor parametrisation and objective functions' selection on the SynRel machine performance. In order to fullfill this scope, three different optimisations have been performed each with specific input parameters, objective functions and constraints.

\section{DESIGN SPECIFICATIONS}

The overall SynRel motor geometry is based on given specifications for traction applications. In Table I, the main machine data are reported. A distributed winding, single layer configuration, is considered, with a maximum current density of $10 \mathrm{~A} / \mathrm{mm}^{2}$, and a water jacket system cooling the machine. Stator and rotor laminations are made of a commercial ferromagnetic material M235-35A.

TABLE I. DESIGN SPECIFICATIONS

\begin{tabular}{|l|c|c|}
\hline \multicolumn{1}{|c|}{ Parameter } & Value & Unit \\
\hline Rated Speed [RPM] & 2500 & $\mathrm{rpm}$ \\
\hline Maximum Speed [RPM] & 10000 & $\mathrm{rpm}$ \\
\hline DC Bus Voltage [V] & 610 & $\mathrm{~V}$ \\
\hline Stator diameter [mm] & 245 & $\mathrm{~mm}$ \\
\hline Rotor diameter [mm] & 160 & $\mathrm{~mm}$ \\
\hline Air gap length [mm] & 0.7 & $\mathrm{~mm}$ \\
\hline Stack kength [mm] & 120 & $\mathrm{~mm}$ \\
\hline Number of slots & 36 & - \\
\hline Number of poles & 6 & - \\
\hline
\end{tabular}




\section{PARAMETRISATION OF THE SYNCHRONOUS RELUCTANCE ROTOR}

For the rotor design of the SynRel motor, there are a number of options. Circular shaped barriers, barriers composed of straight segments and barriers that are shaped according to the field solution are reported in the literature [8][10]. According to the results obtained in [13] and [17], barriers shaped based on the natural distribution of the flux lines in a solid rotor (will be referred as fluid type barriers hereafter) show better performance in terms of average torque, torque ripple and power factor due to the better utilisation of flux and will be the only one considered in this work

The derivation of the fluid type barriers, which are based on Joukowski's flow equations, are mainly described by (1) and (2) in polar coordinates. $\mathrm{C}$ in (1) corresponds to a constant defining a field line. By using (1), $\mathrm{C}$ can be found for a point defined in polar coordinates $(\mathrm{r}, \theta)$ and once the it is found, by using (2) all other points belonging to that field line can be found. Where $\mathrm{r}$ and $\theta$ are radius and flux barrier angle, measured from the center of the shaft, respectively; $R_{\text {shaft }}$ is the radius of the shaft and $p$ is the number of pole pairs.

$$
\begin{gathered}
C=\frac{\sin (\mathrm{p} \theta)\left[\left(\frac{\mathrm{r}}{\mathrm{R}_{\text {shaft }}}\right)^{2 \mathrm{p}}-1\right]}{\left(\frac{\mathrm{r}}{\mathrm{R}_{\text {shaft }}}\right)^{\mathrm{p}}} \\
\mathrm{r}(\theta)=\mathrm{R}_{\text {shaft }} \sqrt{\frac{\mathrm{C}+\sqrt{\mathrm{C}^{2}+4 \sin ^{2}(\mathrm{p} \theta)}}{2 \sin (\mathrm{p} \theta)}}
\end{gathered}
$$

Fig. 1 shows the fluid type barriers and their end-points' angular span in the airgap as alpha $(\alpha)$. The detailed parametrisation procedure is as described below

1. It is common practice to find the field lines passing through a point in the airgap first. By doing so, the field line associated with an end-point will be found by using (1). Afterwards by using (2), polar coordinates of the points can be find for the range $\theta=[0, \pi / p]$.

2. Once the field line corresponding to an end-point is found, thickness of the barrier has to be determined so that two other field lines can be find according to the distance measured from middle-point of the end-point field line.

3. Following the first two steps, it is important define safetv distances between barriers, barrier-rotor barrier-shaft. Another point of consideratic thickness, which defines the distance from $t$ to the rotor surface.

By following the three steps as described abov barriers can be parametrised by imposing sor thicknesses of the barriers. For example, one ca the thickness is equally dividied above and bel point field line, or in a certain ratio. Another rul for defining the barriers' thicknesses as they wil on the end-point position. Maximum thickness of can be automatically calculated by computing between two end-point fluid lines' middle posi safety distances. Once the maximum thicknesses using a single or mutliple variables (equal to th barriers), it is easy to control them with per unit approach
TABLE II. MAXIMUM AND MINIMUM LIMITS OF INPUT VARIABLES

\begin{tabular}{|l|c|}
\hline \multicolumn{1}{|c|}{ Parameter } & Range \\
\hline$\alpha 1$ & $14.81<\alpha 1<37.60$ \\
\hline$\alpha 2$ & $40.00<\alpha 2<50.70$ \\
\hline$\alpha 3$ & $52.30<\alpha 3<58.90$ \\
\hline Insulation ratio along q-axis & $0.2<\mathrm{kwq}<0.8$ \\
\hline
\end{tabular}

where $1 \mathrm{pu}$ is equal to the maximum thickness available. While the procedure above describes a way for defining the barriers, it can be done in numerous ways. For example, instead of going through the steps, iron segments' thicknesses can be defined under each barrier, along with each barrier's thickness and end-point angles making a total of 3 variables per barrier.

It is important to note that although many parametrisations are possible while designing the rotor, the aim is to distribute the barriers in a way that their end-points and thicknesses can be controlled. As investigated in [13], end-point location of the barriers are mainly affecting the torque ripple whereas the distribution of the barriers along the q-axis is mainly affecting the average torque.

For this reason, 4 parameters are selected to represent three barriers: three end-point angles and insulation ratio along the q-axis. According to the maximum thickness available for each barrier, each maximum thickness is multiplied by the insulation ratio which is in the range of [0.2 0.8]. Barrier thicknesses are distributed above and below the end-point fluid line according to the space available in that direction. Shape of the end barrier is always made to be round, by connecting two arcs from ends of the barriers' upper and lower lines which are tangent to the radius defined by the rib thickness. This is shown in Fig. 1, where the red dots are endpoint angles and the dashed lines are the fluid lines of these points. Barriers are drawn here for visualisation purposes with an insulation ratio of 0.5 where the blue lines show the maximum possible thickness of each barrier. Variables representing the barriers are limited in a certain range so that they do not overlap and are in feasible limits, as given in Table II.

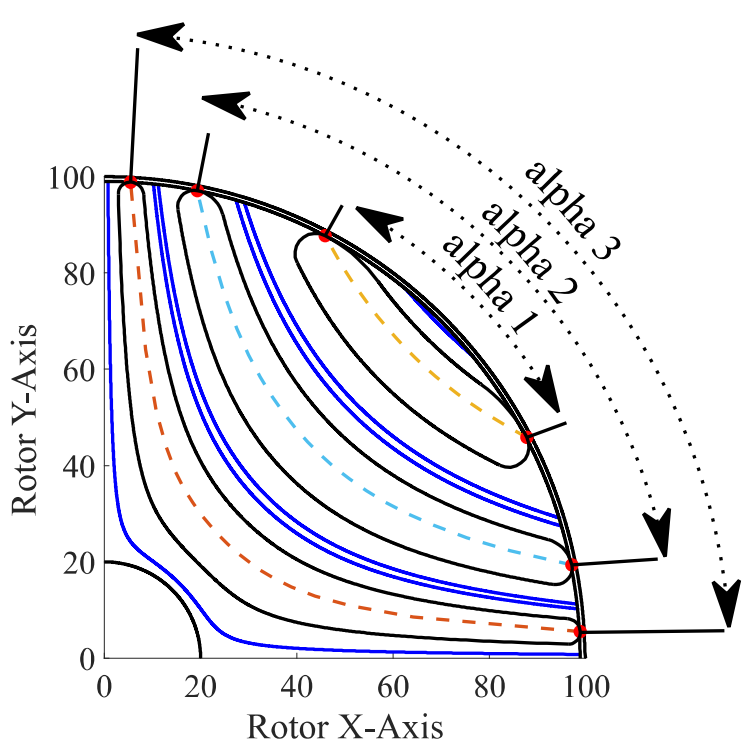

Fig. 1. Parametrization of the fluid type barrier shape. 


\section{OPTIMISATION}

Multi Objective Genetic Algorithm (MOGA) is selected with initial design of experiments generated by using Sobol Sequences according to the maximum and minimum limits of the variables, a total of 4000 designs are considered for each optimisation. A 2D symmetric (one sixth) motor model is used for FEA where the simulation is divided into ten equally spaced points across one slot pitch. The FEA should be performed at the maximum torque per ampere (MTPA) condition, however being the latter too expensive to identify for each rotor candidate, the current phase angle is kept constant at $60^{\circ}$ (electrical degrees). By doing so, optimizing the performance at this angle being fairly close to MTPA, will indirectly optimize the performance at the MTPA condition.

In Fig. 2 the workflow of the optimisation process is illustrated. ModeFrontier is the optimisation software integrating different tools for optimization, including genetic algorithms [18]. Through the software the MATLAB script is launched to generate the machine geometry, analyse it and extract the data to postprocess. Ansys Maxwell is used as the FEA software and it is controlled through a MATLAB script as well as all the preprocessing operations are commanded via the script.

The details of the rotor flux barrier parametrisation have been defined in Section II, and reported in Table II. Three different optimisations have been defined with different objective functions and constraints, while the input variables considered are always the same.

\section{A. Optimisation-1 (O1)}

The first optimisation is the simplest one in terms of objectives and constraints. The objective functions are chosen to maximise the average torque and minimise the torque ripple. The latter has an additional constraint to be respected by means of a threshold value below $10 \%$.

\section{B. Optimisation-2 (O2)}

The second optimisation is formed with the same objectives of maximising average torque and minimising torque ripple as in $\mathrm{O} 1$, but with an additional target function for the

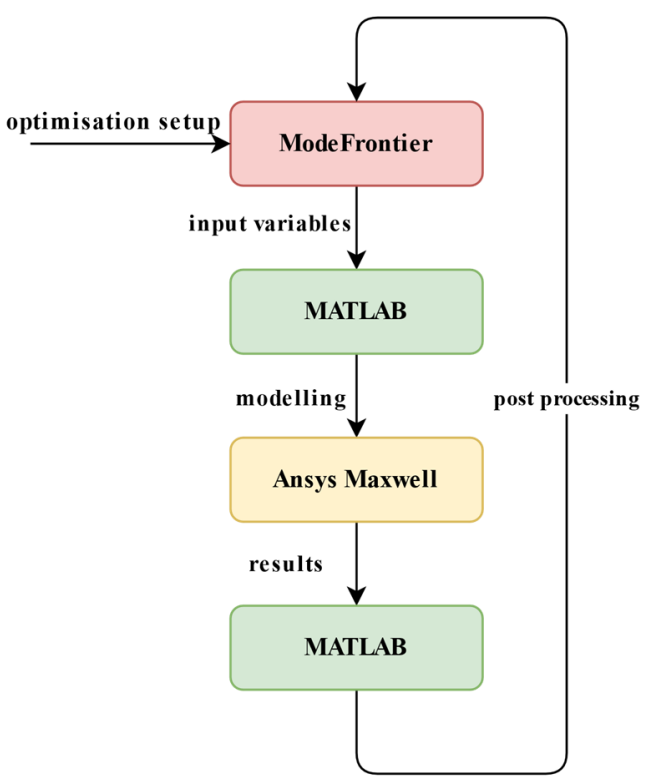

Fig. 2. Workflow of the optimization process minimisation of the iron losses. The torque ripple constraint is always set to $<10 \%$. The aim of $\mathrm{O} 2$ is to investigate the effects of the new objective function (minimisation of losses) on the rotor geometry.

\section{Optimisation-3 (O3)}

The third optimisation has three objectives as the $\mathrm{O} 2$ : maximisation of average torque, minimisation of torque ripple (with $<10 \%$ constraint) and minimisation of losses. In this case, the difference lies in an additional constraint on average torque, whose value will be defined according to the results obtained from $\mathrm{O} 1$ and $\mathrm{O} 2$. With the inclusion of loss minimisation it is possible to have relatively lower average torque values when $\mathrm{O} 2$ is implemented, when compared to O1. To overcome this, forcing the optimisation algorithm to search for designs with higher average torque (above a specific threshold) could lead to different optimal solutions. In the following section the comparison of the results obtained by the three optimisations are reported.

\section{COMPARISON OF OPTIMISATION RESULTS}

\section{A. Optimisation-1 (O1)}

Results obtained with $\mathrm{O} 1$ are presented in Fig. 3. All feasible designs with torque ripple being lower than $10 \%$ are shown with a color scale proportional the insulation ratio and end-point angle of the barriers. As expected, the higher the insulation ratio the higher the average torque. It can be also noticed that end-point angles of the barriers are covering very small ranges. In these small ranges, according to the Fig. 3 (a), (b) and (c), for every insulation ratio, there is a combination of end-point angles which maximises the average torque. This is more evident in Fig. 3 (b) and (c), when the insulation ratio and average torque increase, also the end-point angles change.

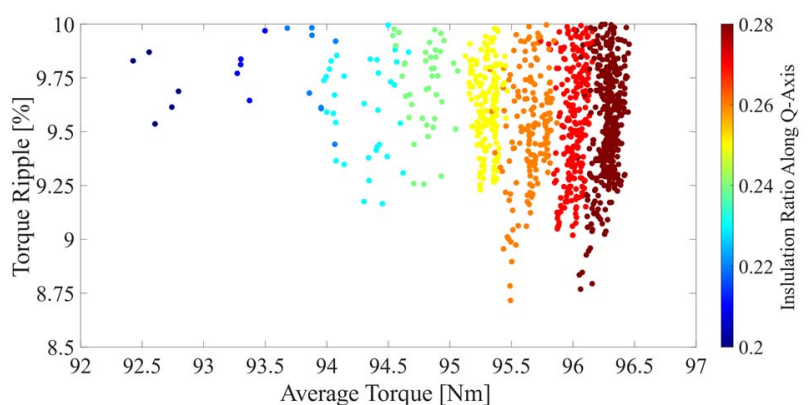

(a)

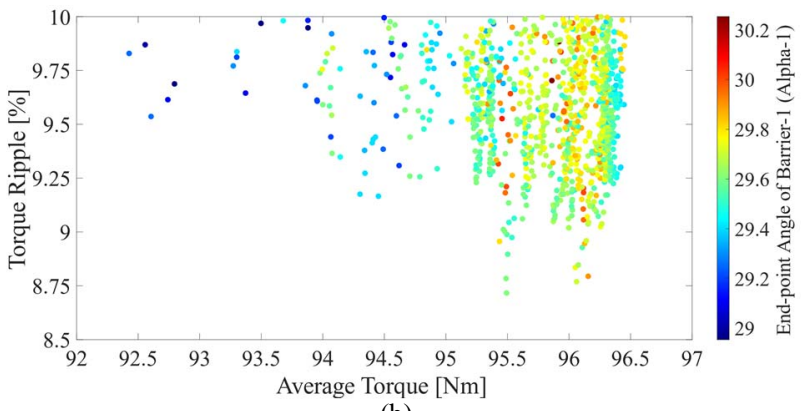

(b) 


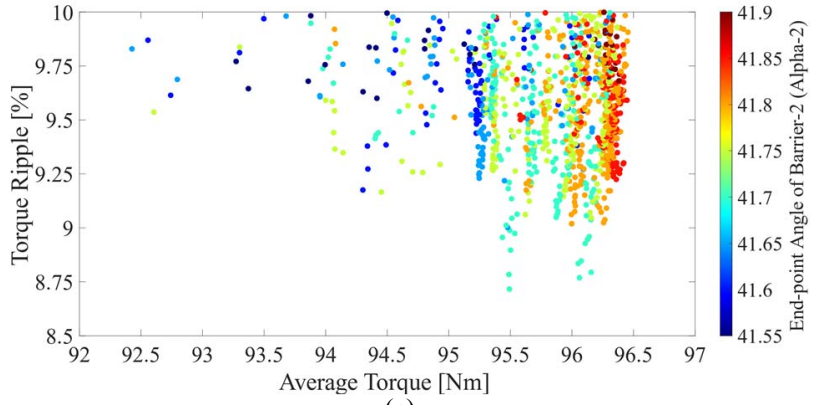

(c)

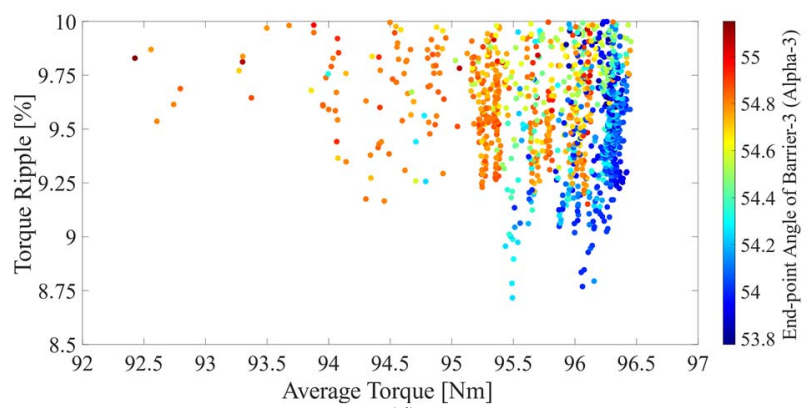

(d)

Fig. 3. Feasible designs with torque ripple lower than 10\%: (a) colored according to insulation ratio (b) colored according to alpha-1, (c) colored according to alpha-2, (d) colored according to alpha-3.

The distribution of flux barrier end-point angles, for certain insulation ratios, also significantly affects the torque ripple. However, the graphs are representing only ripple below $10 \%$, which are respecting the optimization constraint. The average torque moves from about $92.5 \mathrm{Nm}$ towards $96.5 \mathrm{Nm}$, the endpoint angle of the barrier- 2 moves towards its upper range. The end-point of the barrier- 3 instead moves towards its lower range. From Fig. 3 (b) the end-point angle of the barrier-1 has the minimum effect on torque ripple.

\section{B. Optimisation-2 (O2)}

Results of $\mathrm{O} 2$ are given in Fig. 4. The most distinguishable difference between $\mathrm{O} 1$ and $\mathrm{O} 2$ is that the average torque is decreased from a range of $92.5-96.5 \mathrm{Nm}$ to 90.5-92.5Nm range. End-point angles are increased (from $29.5^{\circ}, 41.7^{\circ}$ and $54.5^{\circ}$ to $37^{\circ}, 48.5^{\circ}$ and $58.5^{\circ}$ ) thus the barriers are shifted towards the shaft and the insulation ratio is decreased (from a maximum of 0.28 to maximum of 0.22 ). Because of the barriers being shifted towards the shaft, the length of the flux paths between barriers increases. This leads to a decrease in the saturation level, consequently reducing losses. With the insulation ratio being low, thicknesses of iron segments between the barriers are also increased, causing a further decrease in iron losses.

The effect of end-point angle of barrier-1 (alpha-1) on average torque and torque ripple is again found to be minimum at a certain insulation ratio when Fig. 4 (b) is observed, as it is barely changing with average torque and torque ripple. End-point angle of barrier-2 is seen to be in decrease, for both insulation ratios of 0.2 and 0.21 where the average torque is increasing, as it can be seen in Fig. 4 (c). End-point angle of barrier-2 is decreasing for decreasing torque ripple for the insulation ratios.

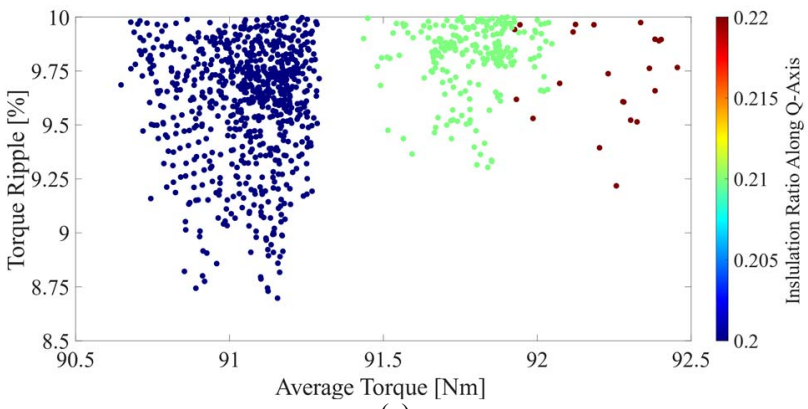

(a)

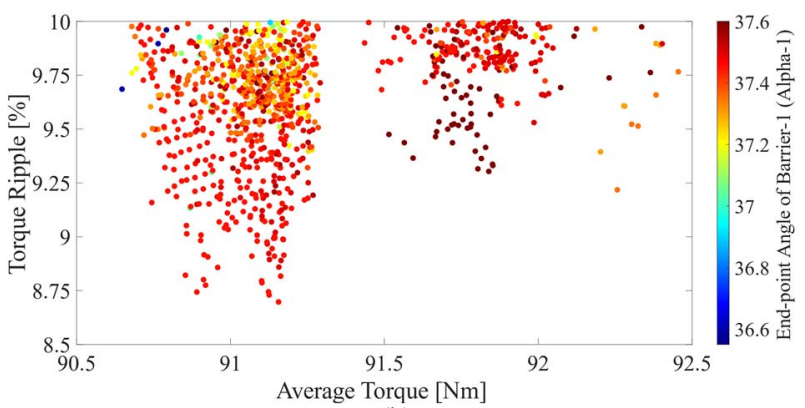

(b)

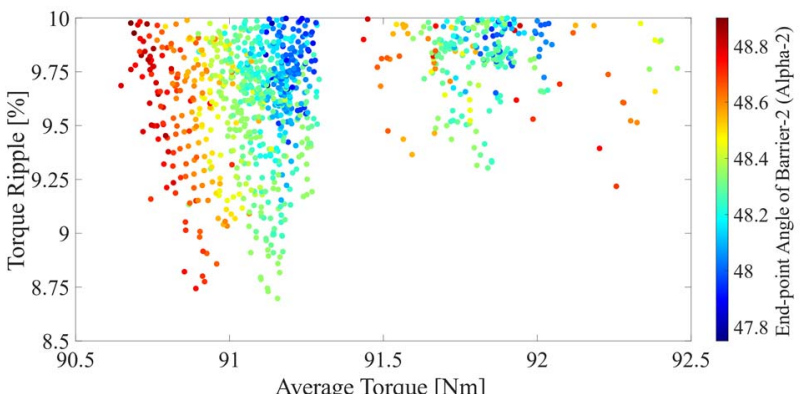

(c)

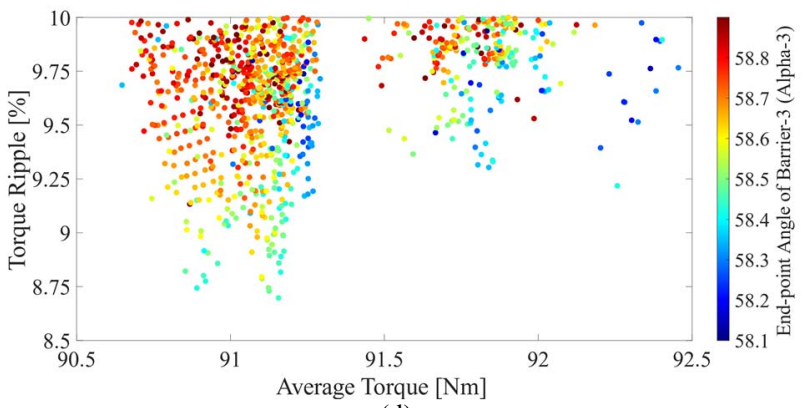

(d)

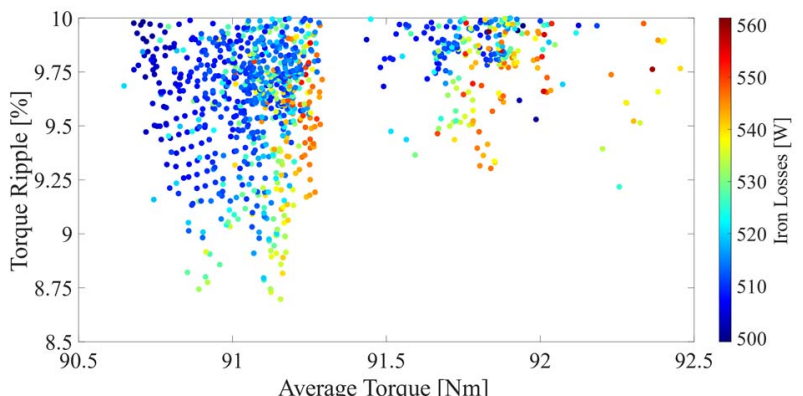

(e)

Fig. 4. Feasible designs with torque ripple lower than $10 \%$ : (a) colored according to insulation ratio (b) colored according to alpha-1, (c) colored according to alpha-2, (d) colored according to alpha-3, (e) colored according to losses. 
In Fig. 4. (e), feasible designs are shown, colored according to the iron losses. It is quite clear that as the average torque increases the losses increase.

\section{Optimisation-3 (O3)}

According to the optimization results $\mathrm{O} 1$ and $\mathrm{O} 2$, a constraint on average torque is imposed to $\mathrm{O} 3$. The only difference between $\mathrm{O} 2$ and $\mathrm{O} 3$ is the average torque constraint $(>95 \mathrm{Nm})$.

Results of $\mathrm{O} 3$ are presented in Fig.5. Feasible designs are shown where the maximum torque ripple is increased to $12 \%$ for demonstration purposes as there are only a few designs with torque ripple lower than $10 \%$. It is seen that average torque values are higher than that of $\mathrm{O} 2$ and similar to $\mathrm{O} 1$, because of the imposed constraint. In order to satisfy the average torque condition, higher values of insulation ratio are obtained (previously maximum insulation value was 0.28 in O1). End-point angles of the barriers are also shifted back towards rotor surface. Iron losses are also increased about $4 \%$ when compared to $\mathrm{O} 2$.

Individual effects of the end-point angles of the barriers are more straightforward than $\mathrm{O} 1$ and $\mathrm{O} 2$. It is seen that the end-point angle of barrier-1, barrier-2 and barrier-3 is in decreasing, increasing and decreasing trend respectively, with increasing average torque and insulation ratio as seen in Fig. 5 (a),(b) and (c). Previously it has been observed that end-point angle of barrier-1 had minor impact on average torque and torque ripple however here that is not the case. Comparing the results of $\mathrm{O} 1$ and $\mathrm{O} 3$, it is seen that end-point angles are quite close to each other but at different insulation ratios. This suggests higher flux amplitudes are flowing through the iron segments surrounding the first barrier and this is probably the reason why the effect of barrier-1 has increased. Another important thing to notice with reference to Fig. 5, although a general increase in the iron losses are observed compared to the results of $\mathrm{O} 2$, it is possible to obtain lower losses with higher insulation ratios by fine-tuning the end-point angles of the barriers.

\section{Further evaluation of optimisation results}

In order to further examine the obtained results, two designs one being the design with lowest torque ripple and the other with the highest average torque are selected on Pareto front of the optimisations, and re-analysed. Summary of these designs are given in Table III. It is seen from the geometries that the barriers of $\mathrm{O} 2$ are very close to shaft as it was previously noted. Also all designs have less thickness of iron segments between barrier-1 and barrier-2, when compared to barrier-2 and barrier-3. Considering all the results carried out and the further analysis conducted on the machines presented in Table III, it can be concluded that optimisation with an objective of minimizing the losses combined with average torque constraint $(\mathrm{O} 3)$ can provide better designs with a best compromise among the target functions.

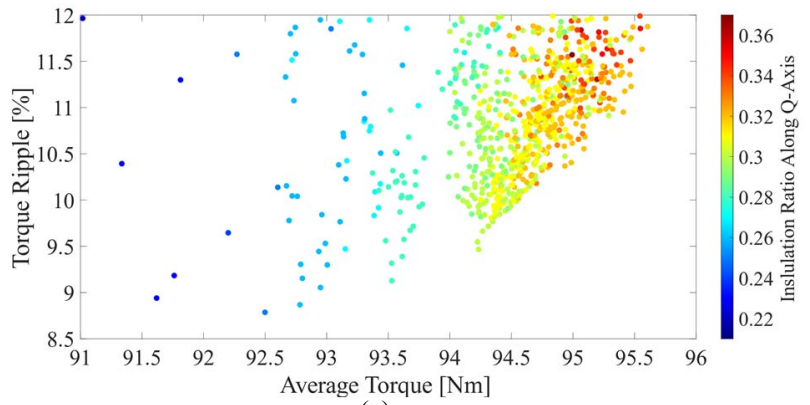

(a)

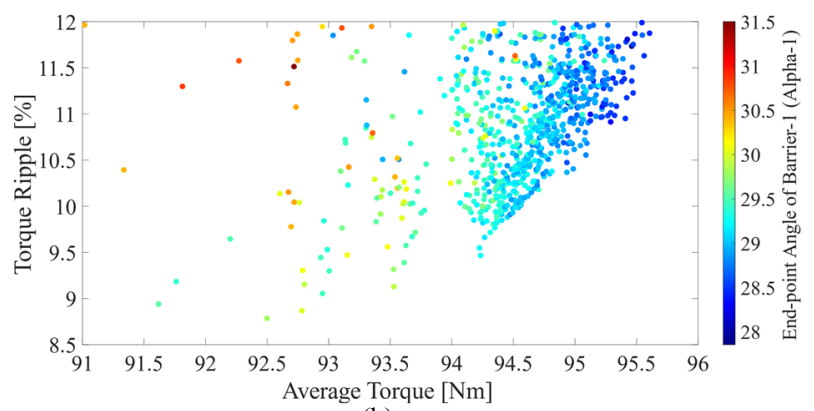

(b)

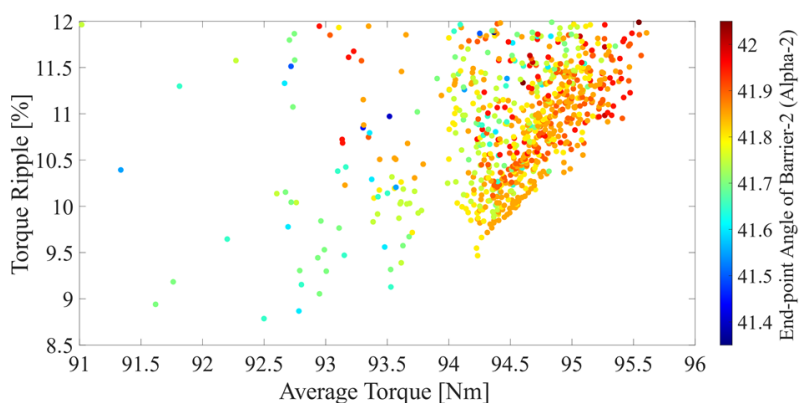

(c)

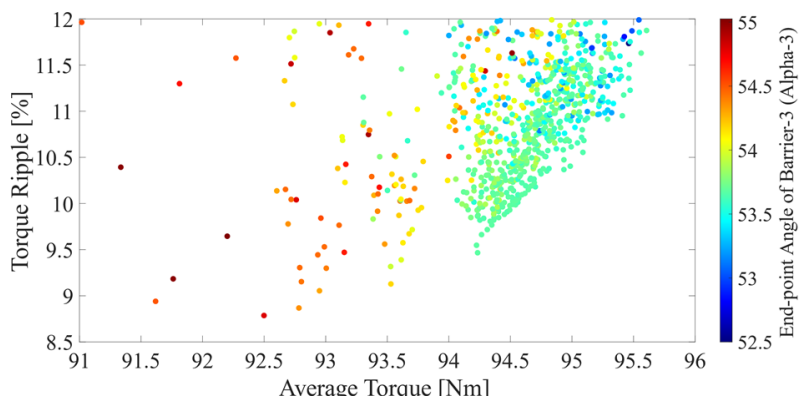

(d)

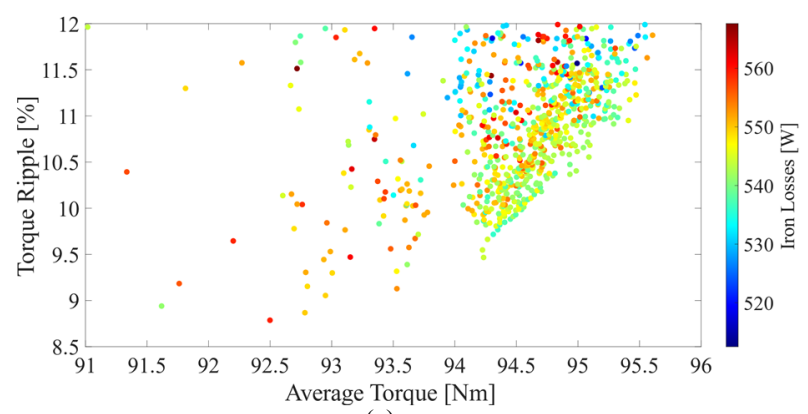

(e)

Fig. 5. Feasible designs with torque ripple lower than 12\%: (a) colored according to insulation ratio (b) colored according to alpha-1, (c) colored according to alpha-2, (d) colored according to alpha-3, (e) colored according to losses. 


\begin{tabular}{|c|c|c|c|c|c|c|}
\hline \multirow[b]{2}{*}{ Parameter } & \multicolumn{2}{|c|}{$\mathrm{O} 1$} & \multicolumn{2}{|c|}{$\mathrm{O} 2$} & \multicolumn{2}{|c|}{$\mathrm{O} 3$} \\
\hline & & & & & & \\
\hline Insulation Ratio & 0.26 & 0.28 & 0.2 & 0.22 & 0.25 & 0.3 \\
\hline $\begin{array}{c}\text { Average Torque } \\
{[\mathrm{Nm}]}\end{array}$ & 92.87 & 93.81 & 91.15 & 92.45 & 92.49 & 94.54 \\
\hline $\begin{array}{c}\text { Torque Ripple } \\
{[\%]}\end{array}$ & 8.98 & 10.6 & 8.69 & 9.76 & 8.78 & 9.98 \\
\hline Core Loss [W] & 552 & 555 & 534 & 540 & 559 & 538 \\
\hline
\end{tabular}

\section{CONCLUSIONS}

In this paper three different optimisations are performed with different objective functions, for the design of a synchronous reluctance machine. First the the parametrisaiton is defined by imposing certain rules to form rotor flux barriers with a maximum number of four geometrical variables. The optimisations results have been presented in detail highighting the effects of both objective functions and constraints, on the rotor geometries and the machines performance, in terms of average torque, torque ripple and iron losses. It is seen that objective functions has a major impact on the optimisation results, which can lead to solutions that are not optimal. It is shown that the best optimisation approach is the one including specific constraints to the objective functions, in this case on both average torque and torque ripple.

\section{REFERENCES}

[1] J. K. Kostko, "Polyphase reaction synchronous motors," in Journal of the American Institute of Electrical Engineers, vol. 42, no. 11, pp. 1162-1168, Nov. 1923, doi: 10.1109/JoAIEE.1923.6591529.J. Clerk Maxwell, A Treatise on Electricity and Magnetism, 3rd ed., vol. 2. Oxford: Clarendon, 1892, pp.68-73.

[2] A. Wexler, "Finite-Element Field Analysis of an Inhomogeneous, Anisotropic, Reluctance Machine Rotor," in IEEE Transactions on Power Apparatus and Systems, vol. PAS-92, no. 1, pp. 145-149, Jan. 1973, doi: 10.1109/TPAS.1973.293606.

[3] A. J. O. Cruickshank, R. W. Menzies and A. F. Anderson, "Axially laminated anisotropic rotors for reluctance motors," in Proceedings of the Institution of Electrical Engineers, vol. 113, no. 12, pp. 2058-2060, December 1966, doi: 10.1049/piee.1966.0358.

[4] A. Fratta, A. Vagati and F. Villata, "On the evolution of AC machines for spindle drive applications," Conference Record of the IEEE Industry Applications Society Annual Meeting, San Diego, CA, USA, 1989, pp. 699-704 vol.1, doi: 10.1109/IAS.1989.96725.

[5] D. Platt, "Reluctance motor with strong rotor anisotropy," Conference Record of the 1990 IEEE Industry Applications Society Annual Meeting, Seattle, WA, USA, 1990, pp. 224-229 vol.1, doi: 10.1109/IAS.1990.152190.

[6] D. A. Staton, T. J. E. Miller and S. E. Wood, "Maximising the saliency ratio of the synchronous reluctance motor," in IEE Proceedings B Electric Power Applications, vol. 140, no. 4, pp. 249-259, July 1993, doi: 10.1049/ip-b.1993.0031.

[7] T. Matsuo and T. A. Lipo, "Rotor design optimization of synchronous reluctance machine," in IEEE Transactions on Energy Conversion, vol. 9 , no. 2 , pp. 359-365, June 1994, doi: 10.1109/60.300136.
[8] R. Moghaddam and F. Gyllensten, "Novel High-Performance SynRM Design Method: An Easy Approach for A Complicated Rotor Topology," in IEEE Transactions on Industrial Electronics, vol. 61, no. 9, pp. 5058-5065, Sept. 2014, doi: 10.1109/TIE.2013.2271601.

[9] G. Pellegrino, F. Cupertino and C. Gerada, "Automatic Design of Synchronous Reluctance Motors Focusing on Barrier Shape Optimization," in IEEE Transactions on Industry Applications, vol. 51, no. 2, pp. 1465-1474, March-April 2015, doi: 10.1109/TIA.2014.2345953.

[10] M. D. Nardo, G. L. Calzo, M. Galea and C. Gerada, "Design Optimization of a High-Speed Synchronous Reluctance Machine," in IEEE Transactions on Industry Applications, vol. 54, no. 1, pp. 233243, Jan.-Feb. 2018, doi: 10.1109/TIA.2017.2758759.

[11] N. Bianchi, M. Degano and E. Fornasiero, "Sensitivity Analysis of Torque Ripple Reduction of Synchronous Reluctance and Interior PM Motors," in IEEE Transactions on Industry Applications, vol. 51, no. 1, pp. 187-195, Jan.-Feb. 2015, doi: 10.1109/TIA.2014.2327143.

[12] M. Barcaro and N. Bianchi, "Air-Gap Flux Density Distortion and Iron Losses in Anisotropic Synchronous Motors," in IEEE Transactions on Magnetics, vol. 46, no. 1, pp. 121-126, Jan. 2010, doi: 10.1109/TMAG.2009.2030675.

[13] R. Rajabi Moghaddam, 'Synchronous Reluctance Machine (SynRM) in Variable Speed Drives (VSD) Applications', PhD dissertation, Stockholm, 2011.

[14] M. Di Nardo, M. Galea, C. Gerada, M. Palmieri, F. Cupertino and S. Mebarki, "Comparison of multi-physics optimization methods for high speed synchrnous reluctance machines," IECON 2015 - 41st Annual Conference of the IEEE Industrial Electronics Society, Yokohama, 2015, pp. 002771-002776, doi: 10.1109/IECON.2015.7392521.

[15] F. Cupertino, G. M. Pellegrino, E. Armando and C. Gerada, "A SyR and IPM machine design methodology assisted by optimization algorithms," 2012 IEEE Energy Conversion Congress and Exposition (ECCE), Raleigh, NC, 2012, pp. 3686-3691, doi: 10.1109/ECCE.2012.6342478.

[16] A. Vagati, G. Franceschini, I. Marongiu and G. P. Troglia, "Design criteria of high performance synchronous reluctance motors," Conference Record of the 1992 IEEE Industry Applications Society Annual Meeting, Houston, TX, USA, 1992, pp. 66-73 vol.1, doi: 10.1109/IAS.1992.244463.

[17] M. Gamba, G. Pellegrino and F. Cupertino, "Optimal number of rotor parameters for the automatic design of Synchronous Reluctance machines," 2014 International Conference on Electrical Machines (ICEM), Berlin, 2014, pp. 1334-1340, doi: 10.1109/ICELMACH.2014.6960355.

[18] G. Poloni and V. Pediroda, "GA Coupled with Computationally Expensive Simulations: Tools to Improve Efficiency" in Genetic Algorithms and Evolution Strategy in Engineering and Computer Science: Recent Advances and Industrial Applications, D. Quagliarella, J. Periaux, C. Poloni, G. Winter, John Wiley\&Sons, 2000. 